Case Report

\title{
Treatment of Multiple Arterial Aneurysms in Patient with Polyaneurysmal Disease: Case Report
}

\author{
Kimã Barbosa Monteiro Meira ${ }^{1}$, Rodrigo Nóbrega Bandeira ${ }^{1}$, Tainá Louise Dantas Barreto ${ }^{2}$, \\ Ranieri Dutra Nogueira ${ }^{2}$, Felipe Ramalho de Morais ${ }^{1}$, Caio César Vaz Lacet Gondim², \\ Amanda Morimitsu ${ }^{2}$, Sérgio Ricardo Ferreira Vieira ${ }^{3}$, Francisco Chavier Vieira Bandeira ${ }^{1}$, \\ Paulo Roberto da Silva Lima ${ }^{2, *}$
}

${ }^{1}$ Department of Medicine, Federal Universety of Paraíba (UFPB), João Pessoa - PB, Brazil

${ }^{2}$ Department of Medicine, Universetary Center of João Pessoa (UNIPÊ), João Pessoa - PB, Brazil

${ }^{3}$ Department of Medicine, Faculty of Medical Sciences of Paraíba (FCM), João Pessoa - PB, Brazil

\section{Email address:}

paulovascular@hotmail.com(P.R.da S.Lima)

${ }^{*}$ Corresponding author

\section{To cite this article:}

Kimã Barbosa Monteiro Meira, Rodrigo Nóbrega Bandeira, Tainá Louise Dantas Barreto, Ranieri Dutra Nogueira, Felipe Ramalho de Morais, Caio César Vaz Lacet Gondim, Amanda Morimitsu, Sérgio Ricardo Ferreira Vieira, Francisco Chavier Vieira Bandeira, Paulo Roberto da Silva Lima. Treatment of Multiple Arterial Aneurysms in Patient with Polyaneurysmal Disease: Case Report. Journal of Surgery.

Vol. 6, No. 2, 2018, pp. 53-57. doi: 10.11648/j.js.20180602.15

Received: February 19, 2018; Accepted: March 11, 2018; Published: April 3, 2018

\begin{abstract}
Polyneurysmal dystrophy is defined as the clinical entity characterized by the presence of multiple arterial lesions in different sections of the arterial tree in a simultaneous or sequential manner, excluding uniquely bilateral and multilobulated aneurysms [1,2]. The incidence of multiple aneurysms in the United States is $0.01 \%$ [3] to 3.9\% [4]. These aneurysms are caused by: atherosclerosis [4,5], changes in elastic fibers (ectasic medial dystrophy) [6], Polyarteritis Nodosa, Takayasu's arteritis, Behçet's disease, Marfan's syndrome, trauma and infection [7]. We performed a search on the PubMed and Bireme databases, where we found 17 articles from 1963 to 2017. This work is a case report. A 79-year-old male, a former smoker, hypertensive. He was undergoing colored arterial Doppler ultrasonography that revealed fusiform aneurysms in popliteal arteries (AAP) and femoral arteries (AAF) bilaterally. A Computed tomography angiography (CTA) showed Abdominal Aortic Aneurysm (AAA) type IV (Crawford) of $4.5 \mathrm{~cm}$ in diameter, iliac arteries and common femoral arteries enlarged. Fifteen days before the starting of studies of this case, the patient presented fungal lesion in right foot evolving with critical ischemia. We opted for conventional surgery. A femoral-pedal bypass with ex-vivo saphenous vein without valves, in the right lower limb, with the exclusion of AAF and AAP, was also performed, in addition to amputation of the 5th right toe. The colored arterial Doppler ultrasonography of the RLL at the 30th day after the surgery evidenced exclusion of AAF, patent bypass, AAP with low flow and thrombi in it. Forty days after the surgery in RLL, he evolved with pain, pallor and hypothermia in Left Lower Limb (LLL). A colored arterial Doppler ultrasonography of the LLL revealed acute occlusion of the left popliteal artery and a Left Femoral Artery Aneurysm. We have performed a femoral-pedal bypass in Left Lower Limb, with exclusion of AAF and left AAP. About 3 (three) months after the last surgery, the patient evolved well, with peripheral pulses preserved. But during preparation for the correction of the thoracic aneurysm the patient developed mesenteric thrombosis due to the mural thrombi of the abdominal aortic aneurysm; he was submitted to exploratory laparotomy and resection of $70 \mathrm{~cm}$ of small intestine. During waiting for customized endoprosthesis to treat abdominal aortic aneurysm, the patient had passed away. We cannot waste time in the treatment of this disease, and it is extremely difficult to predict which of the aneurysms needs to be treated first.
\end{abstract}

Keywords: Polyaneurysmal, Polyianeurysmatic, Multiple Aneurysms, Ectasic Medial Dystrophy 


\section{Introduction}

Polyneurysmal dystrophy is defined as the clinical entity characterized by the presence of multiple arterial lesions in different sections of the arterial tree in a simultaneous or sequential manner, excluding uniquely bilateral and multilobulated aneurysms $[1,2]$.

The incidence of multiple aneurysms in the United States is $0.01 \%$ [3] to $3.9 \%$ [4]. These aneurysms are caused by: atherosclerosis $[4,5]$, changes in elastic fibers (ectasic medial dystrophy) [6], Polyarteritis Nodosa, Takayasu's arteritis, Behçet's disease, Marfan's syndrome, trauma and infection [7]. Most of patients are between 60 and 70 years old [5].

As the Polyaneurysmal dystrophy has its origin of multiple components: there is an abnormal constitution in the artery with dolicho and then megadolichoarteries on which appear at middle age, multiple aneurysms, often bilateral and symmetrical, with thin walls, susceptible to rupture or thrombosis [6], due to decrease of elastic fibers and muscle cells in the medial layer of the artery [6]. By the literature, the usual sites are trunks and terminal aorta, and when they appear in limbs, frequently they are bilateral and symmetrical [6].

Megadolichoarter should not be confused with dolichoarteres [7]. The first ones are of big caliber before lying down and becoming tortuous, the seconds lengthen remaining of normal caliber [7]. The dolichoarteres are congenital (forms of the child), dysplastic or acquired (elderly, hypertensive) [7]. They come in the form of tortuosities (in S or C), loops or coiling (winding in a circle, in turn) and kinking or stenosing plications [7].

Dysplasia, arterial dystrophy? In the first case, it is an anomaly of development of the artery, ante or postnatal. In the second case, the anomaly results from an acquired process, here degradation of the media then atherosclerosis [7].

The vast majority of aneurysms are called atheromatous (term discussed because atherosclerosis is secondary to dystrophy of the wall) [7]. Some atheromatous AAA is in an inflammatory form [7].

Nonatheromatous aneurysms form a very heterogeneous framework of rather infrequent lesions: true and false aneurysms of Behçet's disease, infectious aneurysms, aneurysms on arterial dysplasia (EhlersDanlos type IV, DFM), inflammatory arteritis, dysembryoplasias (persistent sciatic artery) [7]. False aneurysms are called aneurysmal lesions that do not have a clean wall; they are most often iatrogenic [7].

\section{Materials and Methods}

We performed a search on the PubMed and Bireme databases, where we used the keywords: polyaneurysmal, polyianeurysmatic and multiple aneurysms, where we found 17 articles from 1963 to 2017. This work is a case report.

\section{Results}

A 79-year-old male, a former smoker, hypertensive, started with pain in the right calf one month ago. He was undergoing colored arterial Doppler ultrasonography that revealed fusiform aneurysms in popliteal arteries (AAP) and femoral arteries (AAF) bilaterally. A Computed tomography angiography (CTA) of the abdominal aorta, iliac arteries and arteries from lower limbs showed Abdominal Aortic Aneurysm (AAA) type IV (Crawford) of $4.5 \mathrm{~cm}$ in diameter (Figure 1), iliac arteries and common femoral arteries enlarged (Figure 2-4). Fifteen days before the starting of studies of this case, the patient presented fungal lesion in right foot evolving with critical ischemia. Due to the large extension of the aneurysms in the lower limbs we opted for conventional surgery. During the surgery, we identified a diffuse atherosclerosis and right femoral artery enlarged. A femoral-pedal bypass with ex-vivo saphenous vein without valves, in the right lower limb (RLL), with the exclusion of AAF and AAP, was also performed, in addition to amputation of the 5th right toe. The colored arterial Doppler ultrasonography of the RLL at the 30th day after the surgery evidenced exclusion of AAF, patent bypass, AAP with low flow and thrombi in it. Forty days after the surgery in RLL, he evolved with pain, pallor and hypothermia in Left Lower Limb (LLL). A colored arterial Doppler ultrasonography of the LLL revealed acute occlusion of the left popliteal artery and a Left Femoral Artery Aneurysm. We have performed a femoral-pedal bypass with ex-vivo saphenous vein without valves in Left Lower Limb, emergentially, with exclusion of AAF and left AAP. In the 10th day after the surgery, the patient evolves with hematoma in the proximal region of the operative wound, after a falling of the own height. It was submitted to vascular exploration with hematoma drainage. About 3 (three) months after the last surgery, the patient had a brachial ankle index (BAI) of 0.94 in both lower limbs; stable, without complaints and occlusion of the aneurysms in both lower limbs. We have had delivered the patient to the thoracic surgeon for correction of ascending aortic aneurysm (figure 5). Correction of aneurysms by the open technique was performed successfully and confirmed by postoperative ultrasound imaging. The patient evolved well, with peripheral pulses preserved. But during preparation for the correction of the thoracic aneurysm the patient developed mesenteric thrombosis due to the mural thrombi of the abdominal aortic aneurysm; he was submitted to exploratory laparotomy and resection of $70 \mathrm{~cm}$ of small intestine (Figure 6). He beared the surgery and recorvered himself well. Due to the intestinal necrosis due to mesenteric thrombosis, we chose to first treat abdominal aortic aneurysm (type IV Crawford classification) prior to the ascending aortic aneurysm, however, during waiting for customized endoprosthesis, the patient had rupture of the abdominal aortic aneurysm and passed away.

\section{Discussion}

Contrary to the study of Loire (1992) [6], our clinical case favored atherosclerotic cause as well as the articles of Dent (1972) [4] and Pelissier (1975) [5], since the histopathological 
examination of a fragment of the left femoral artery of our patient revealed only atherosclerotic origin.

Surgical precautions are necessary during resection of aneurysms, given the fineness and fragility of the arterial walls despite of the presence of atherosclerosis layers [6]. In our case, we could observe this as well, the arterial walls were thin and dolicho or megadolichoarteries, however they had plaques of atheroma, most of them calcified. As Loire (1992) [6] warns, we must take pay attention in the distribution and scalability of lesions and to that it is requiring complete arterial inventory and accurate monitoring of the subjects' fate [6].

Due to the age of our patient, their physical and cardiac conditions and due to the surgical time of each surgery, several co-morbidities of the most recent surgeries, we opted to perform the treatment of the aneurysms in a staggered way, following the order of priority of the aneurysms, namely that: symptoms, is causing complications and size of the aneurysm.

The endovascular treatment of lower limb aneurysms was not considered due to the large extent of coverage that would be required to treat the aneurysms, thereby eliminating a great number of collateral arteries necessary for the nutrition of the surrounding tissues, as well as the disproportion between segment dolicho and normal artery. Endovascular treatment had been proposed for the abdominal aortic aneurysm and for the ascending aorta it would be open surgery (traditional).

\section{Conclusion}

We cannot waste time in the treatment of this disease, and it is extremely difficult to predict which of the aneurysms needs to be treated first. Although we have treated the symptomatic aneurysms, we were defeated by the logistics issue in our country. The literature has few data available [1-17], and further studies are needed to clarify its pathogenesis and treatment.

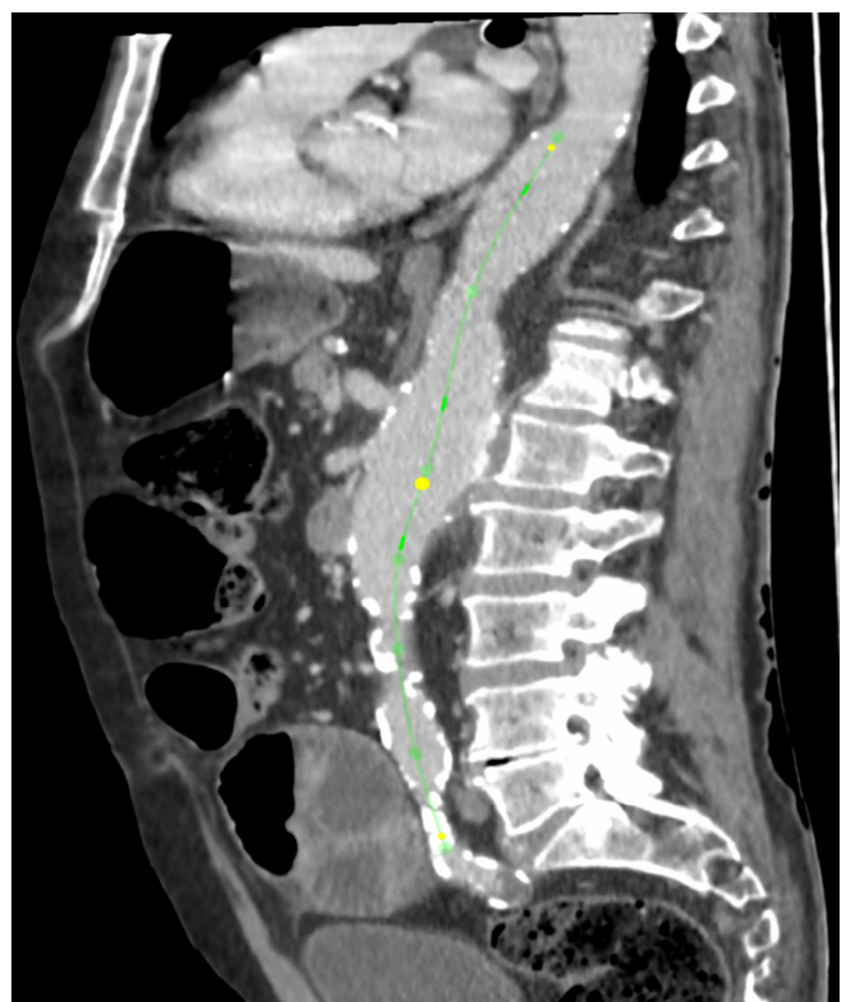

Figure 1. Abdominal Aortic Aneurysm (AAA) type IV (Crawford) of $4.5 \mathrm{~cm}$ in diameter.

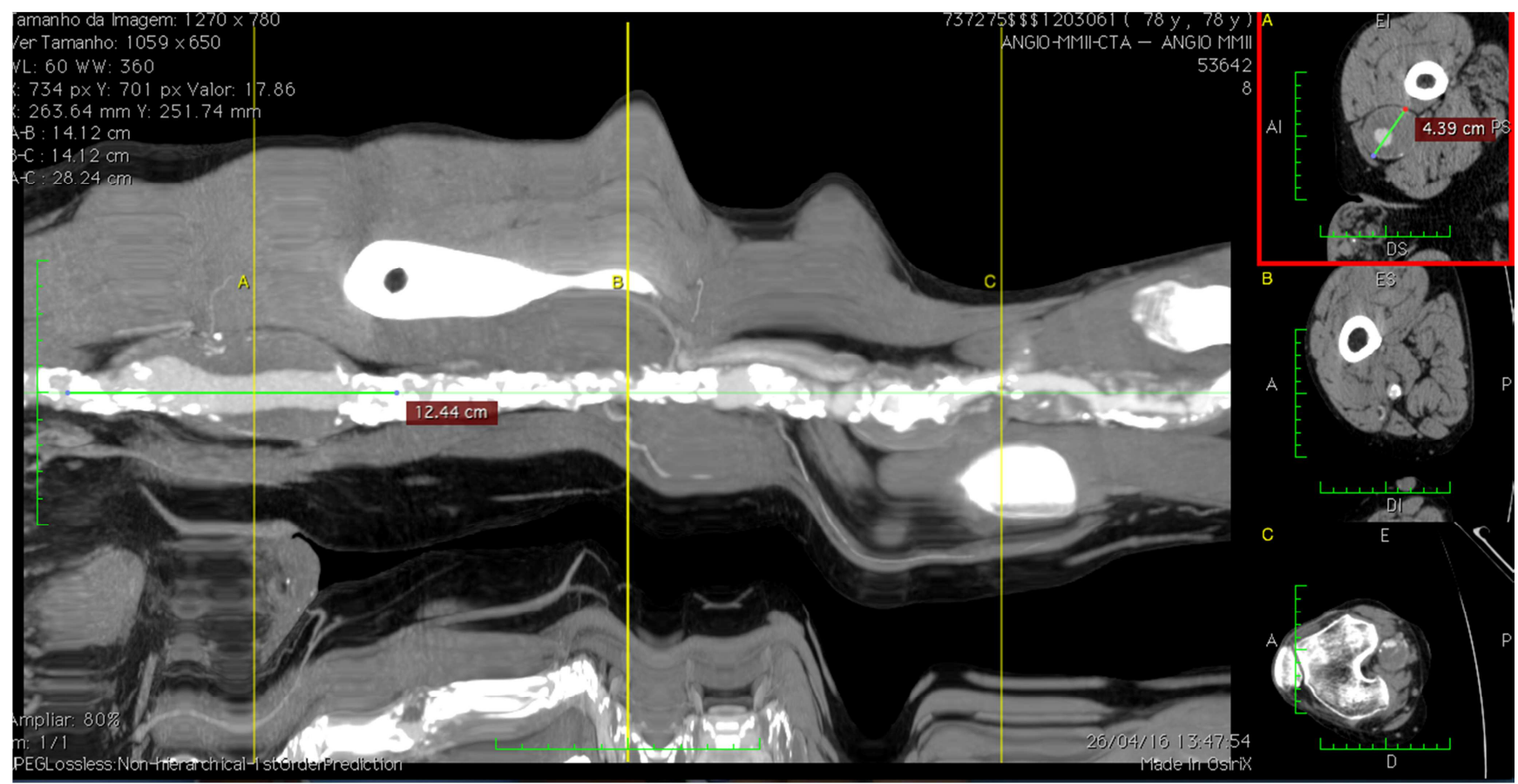

Figure 2. Femoral Artery Aneurysm (AAF) and Popliteal Artery Aneurysm (AAP) - Right Lower Limb 


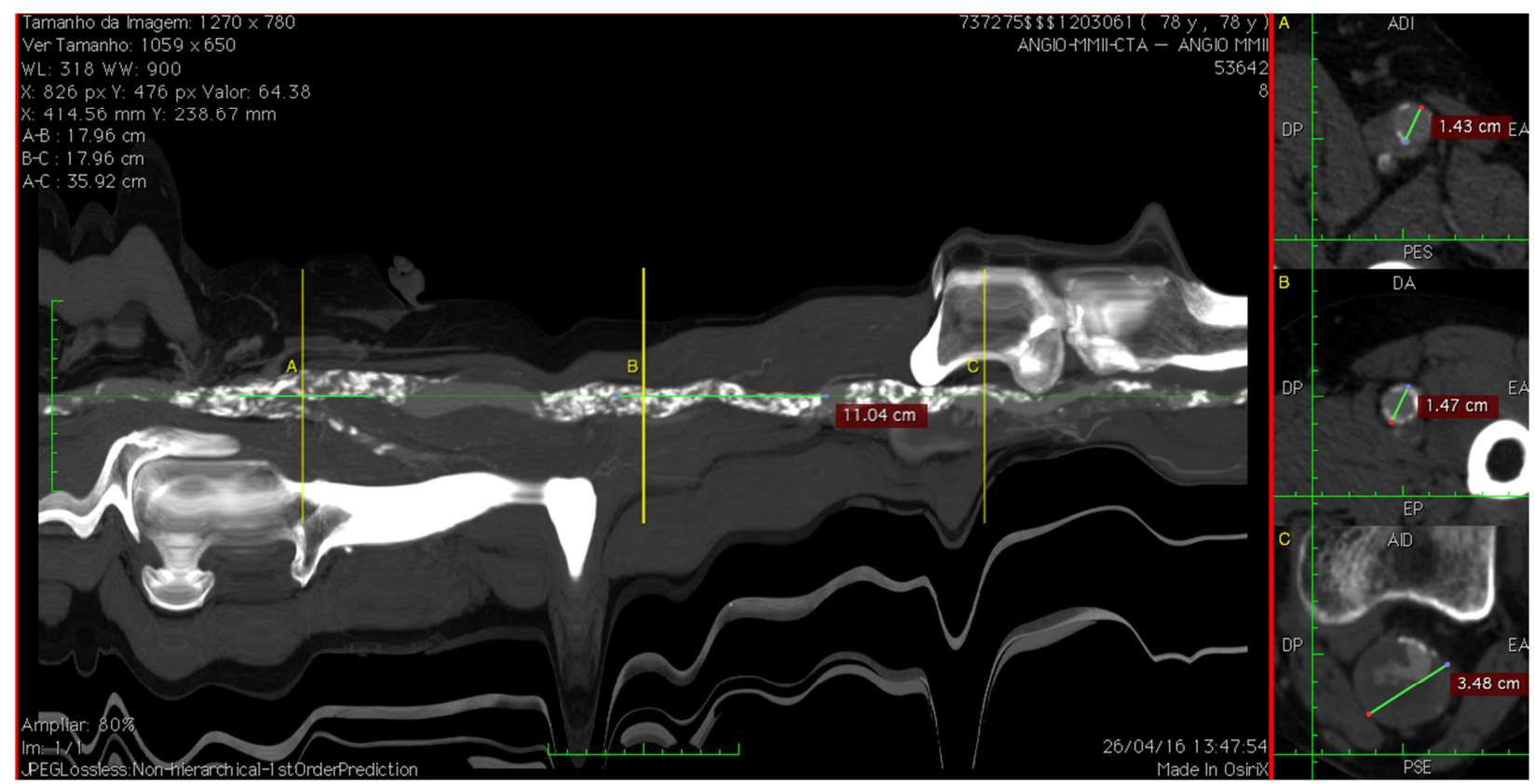

Figure 3. Popliteal Artery Aneurysm (AAP) in Left Lower Limb.

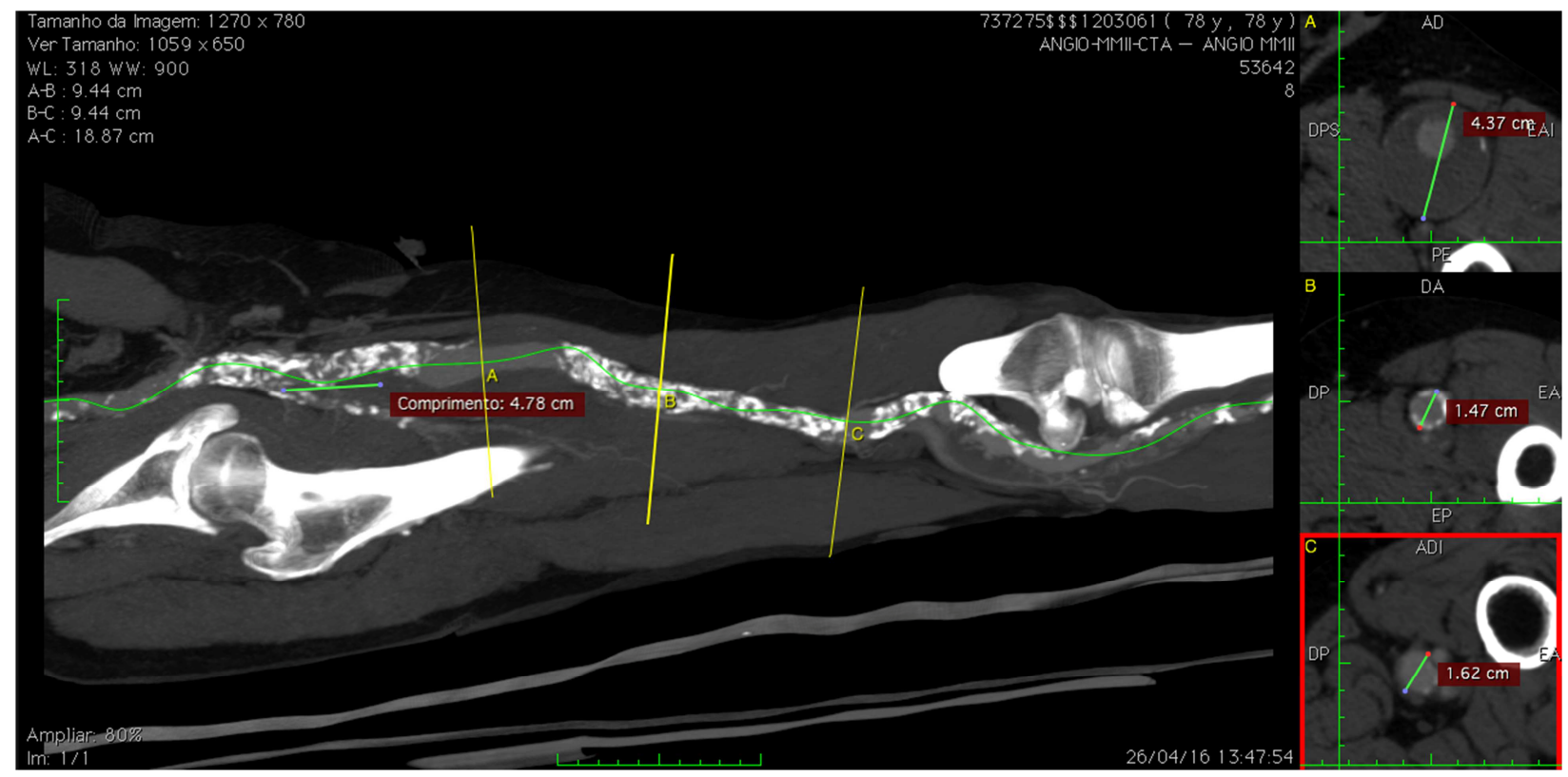

Figure 4. Femoral Artery Aneurysm (AAF) in Left Lower Limb.

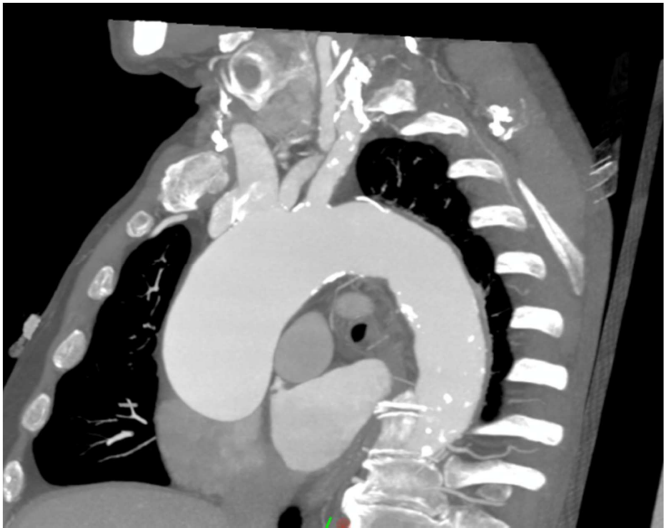

Figure 5. Ascending Aortic Aneurysm.

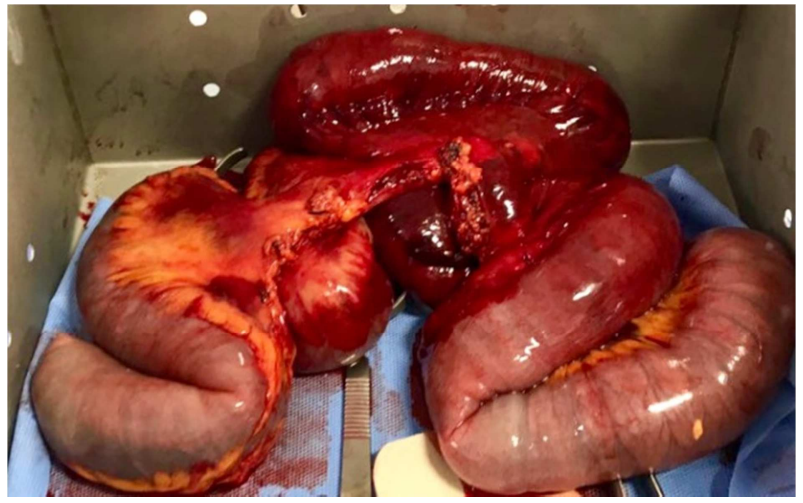

Figure 6. The resection of $70 \mathrm{~cm}$ of small intestine. 


\section{Authors' Contribution}

Kimã Barbosa Monteiro Meira - bibliographic survey, written and assisted in bypass surgeries

Rodrigo Nóbrega Bandeira - bibliographic survey, written and assisted in bypass surgeries

Tainá Louise Dantas Barreto - bibliographical and written surveys

Ranieri Dutra Nogueira - bibliographical and written surveys

Felipe Ramalho de Morais - bibliographical and written surveys

Caio César Vaz Lacet Gondim - bibliographical and written surveys

Amanda Morimitsu - bibliographical and written surveys

Sérgio Ricardo Ferreira Vieira - anesthetist in bypasses and traumatic hematoma

Francisco Chavier Vieira Bandeira - 1st assistant in bypass surgery

Paulo Roberto da Silva Lima - bibliographic survey, organization and writing of article, besides being the main surgeon in the surgeries

\section{References}

[1] Martínez Pérez M. Distrofia polianeurismática. En: Estevan Solano JM. Tratado de aneurismas. Barcelona: Uriach, 1997. p. 497-507.

[2] Mesh LC, Graham ML. Aortic aneurysm, arteriomegaly, and aneurysmosis. En: Ernest BC, Stanley CJ. Mosby Current Therapy in Vascular Surgery (3ra Ed). St. Louis: editorial; 1995:292-96.

[3] Mei F, Yu M, Li Y, Jin B, Ouyang C. Treatment of multiple aneurysms. Ann Vasc Surg. 2014; 28 (8):1937 e13-7.

[4] Dent TL, Lindenauer SM, Ernst CB, Fry WJ. Multiple arteriosclerotic arterial aneurysms. Arch Surg. 1972; 105 (2):338-44.

[5] Pelissier P. Les dolichomega arteres (à propos de 28 observations). Lyon 1975.
[6] Loire R, Descotes J. [Polyaneurysmal dystrophy (ectatic medial dystrophy)]. Ann Cardiol Angeiol (Paris). 1992; 41 (8):443-8.

[7] Becker F. Anévrisme, artériomégalie, dolichoartère, dysplasie artérielle... de quoi parle-t-on? Journal des Maladies Vasculaires. 2015; 40 (2):70-1.

[8] Sugiura H, Hosoda Y. [Histopathological and immunohistochemical diagnosis of intractable vasculitis syndromes]. Nihon Rinsho. 1994; 52 (8):2034-40.

[9] Alvarez Garcia L, Vidal Fernandez P, Garcia Gimeno MF, Gonzalez Arranz MA, Gonzalez Gonzalez ME, Lopez Garcia D, et al. Aortic polyaneurysmal disease: case report. J Thorac Dis. 2017; 9 (Suppl 6):S544-S6.

[10] Chen JY, Tsai YS, Li YH. Multiple arterial aneurysms in a patient with Behcet's disease. Eur Heart J Cardiovasc Imaging. 2016; 17 (5):587.

[11] Defraigne JO, Vasquez C, Limet R. Ruptured aneurysm of the profunda femoral artery associated with polyaneurysmal disease. Acta Chir Belg. 1997; 97 (2):93-6.

[12] English WP, Edwards MS, Pearce JD, Mondi MM, Hundley JC Hansen KJ. Multiple aneurysms in childhood. J Vasc Surg. 2004; 39 (1):254-9.

[13] Harbuzariu C, Duncan AA, Bower TC, Kalra M, Gloviczki P. Profunda femoris artery aneurysms: association with aneurysmal disease and limb ischemia. J Vasc Surg. 2008; 47 (1):31-4; discussion 4-5.

[14] Henry WJ. Multiple Aneurysm Formation in a Young Man: A Case Report. Ann Surg. 1963; 158:1043-6.

[15] Lizame MLG, Musenden OE, Brínguez YP, Torres DC, Valadez MH. Distrofia polianeurismática: presentacíon de un caso. Rev cuba angiol y cir vasc. 2007; 8 (1):1-3.

[16] Schiller M, Gordon R, Shifrin E, Abu-Dalu K. Multiple arterial aneurysms. J Pediatr Surg. 1983; 18 (1):27-9.

[17] Takagi H, Mori Y, Manabe H, Hirose H. Multiple arterial aneurysms. J Vasc Surg. 2003; 38 (6):1440. 